\title{
$17^{\text {th }}$ INTERNATIONAL MULTIDISCIPLINARY
}

\section{SCIENTIFIC GEOCONFERENCE SGEM 2017}

CONFERENCE PROCEEDINGS VOLUME 17

Nano, Bio, Green and Space Technologies for a Sustainable Future Issue 63

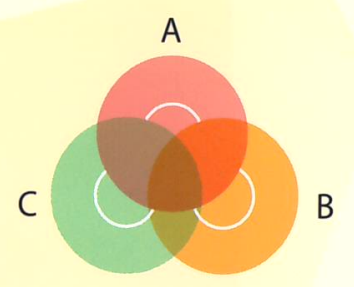

MICRO AND NANO TECHNOLOGIES ADVANCES IN BIOTECHNOLOGY GREEN BUILDINGS TECHNOLOGIES AND MATERIALS GREEN DESIGN AND SUSTAINABLE ARCHITECTURE ANIMALS AND SOCIETY 


\section{DISCLAIMER}

This book contains abstracts and complete papers approved by the Conference Review Committee. Authors are responsible for the content and accuracy.

Opinions expressed may not necessarily reflect the position of the International Scientific Council of SGEM.

Information in the SGEM 2017 Conference Proceedings is subject to change without notice. No part of this book may be reproduced or transmitted in any form or by any means, electronic or mechanical, for any purpose, without the express written permission of the International Scientific Council of SGEM.

Copyright (C) SGEM2017

All Rights Reserved by the International Multidisciplinary Scientific GeoConferences SGEM Published by STEF92 Technology Ltd., 51 "Alexander Malinov" Blvd., 1712 Sofia, Bulgaria Total print: 5000

ISBN 978-619-7408-29-4

ISSN 1314-2704

DOI: $10.5593 /$ sgem $2017 \mathrm{H} / 63$

INTERNATIONAL MULTIDISCIPLINARY SCIENTIFIC GEOCONFERENCE SGEM Secretariat Bureau

E-mail: hofburg@sgemviennagreen.org

URL: www.sgemviennagreen.org 
COMMUNE, Lecturer Alina Maria Tenche-Constantinescu PhD, Prof. Gheorghe Florian Borlea PhD, Assoc. Prof. Cornelia Hernea PhD, Prof. Silvica Oncia PhD, Banat University of Agricultural Sciences and Veterinary Medicine King Michael I of Romania from Timisoara, Romania 819

103. "URBAN ACUPUNCTURE": DUAL SPACES AS A STRATEGY FOR URBAN RESILIENCE, Dr Anna Porebska, Prof. Paola Rizzi, Cracow University of Technology, Poland 827

104. ECO-BUILDINGS SUSTAINABLE DESIGN IN LINKAGE WITH REMOTE SENSING AND UNDERGROUND URBAN AGRICULTURE, Justyna Kobylarczyk, Ewa Glowienka, Jan W. Dobrowolski, Slawomir Mikrut, Kielce University of Technology, Poland. 835

105. ECOLOGY AS AN ICON OF THE CONTEMPORARY DEVELOPMENT OF METROPOLISES, Boguslaw Podhalanski, Cracow University of Technology, Poland 845

106. ENVIRONMENTAL QUANTITY SURVEY FOR BUILDINGS GPP REQUIREMENTS, Prof. Manuela Rebaudengo Prof. Fabio Manzone Prof. Carlo Caldera Prof. Francesco Prizzon, Politecnico di Torino, Italy .853

107. MUNICIPAL SUSTAINABLE DEVELOPMENT GOVERNANCE INDICATOR SYSTEM INNOVATION: INTRODUCTION AND ASSESSMENT, Janis Kaulins, University of Latvia, Latvia .861

108. EVOLUTION AND PROBLEMS CONCERNING THE DEVELOPMENT OF TIMISOARA METROPOLITAN AREA (ROMANIA). A CASE STUDY GIROC COMMUNE, Assoc. Prof. Szekely Gabriel PhD, Lecturer Alina Maria Tenche-Constantinescu $\mathrm{PhD}$, Banat University of Agricultural Sciences and Veterinary Medicine King Michael I of Romania from Timisoara, Romania 871

109. MANAGEMENT OF THE GRASSLANDS SURFACES FOR A DESCRIPTIVE CASE IN BANAT PLAIN ROMANIA, Samfira Ionel, Barliba Costel, Butnariu Monica, Banat s University of Agricultural Sciences and Veterinary Medicine from Timisoara, Romania 881

110. GREEN BIM - A LEAN METHODOLOGY TO SUPPORT SUSTAINABILITY ASSESSMENT PROTOCOLS, Assoc. Prof. Dr. Fulvio Re Cecconi, Dr. Lavinia Chiara Tagliabue, Dr. Sebastiano Maltese, Full Prof. Dr. Angelo Luigi Camillo Ciribini, Assoc. Prof. Dr. Iva Kovacic, Politecnico di Milano, Italy .889

111. GREEN MOORING LOCATION FOR BOATS, Assoc. Prof. Modiga Alina, Assoc. Prof. Popescu Gabriel, University "Dunarea de Jos", Romania 897 


\title{
GREEN BIM - A LEAN METHODOLOGY TO SUPPORT SUSTAINABILITY ASSESSMENT PROTOCOLS
}

\author{
Assoc. Prof. Dr. Fulvio Re Cecconi ${ }^{1}$ \\ Dr. Lavinia Chiara Tagliabue ${ }^{2}$ \\ Dr. Sebastiano Maltese ${ }^{1}$ \\ Full Prof. Dr. Angelo Luigi Camillo Ciribini ${ }^{2}$ \\ Assoc. Prof. Dr. Iva Kovacic ${ }^{3}$ \\ ${ }^{1}$ Politecnico di Milano, Italy \\ ${ }^{2}$ University of Brescia, Italy \\ ${ }^{3}$ Vienna University of Technology, Austria
}

\begin{abstract}
This research aims at exploiting COBie to develop a lean methodology to rate existing assets using sustainability assessment protocols like LEED, BREEAM, DGNB and CESBA. The methodology includes an efficient information management process in a BIM-oriented framework. BIM processes are frequently considered too much expensive and effort consuming for being applied in the retrofit or in the management of existing buildings because they demand a lot of data. The proposed methodology is founded on the idea that a COBie collection of spreadsheets is a BIM model even if it does not have any $3 \mathrm{D}$ geometrical information, which are often very expensive to collect for existing buildings. The COBie model may be populated of data coming from different sources, like the analysis of existing documents, inexpensive visual survey, interviews with peoples living the asset, etc.. The COBie model is used to store both information to be used in sustainability rating and the (partial) results coming from calculations. The methodology is presented here with the help of a case study: the rating of an existing building in the north of Italy, currently used as a private gym, using the CESBA protocol. The existing documents, managed in a Document Management System, have been analyzed and then all the information needed for the CESBA protocol have been transferred to the COBie spreadsheet, being able to satisfy (in terms of data requirements) the $85 \%$ of the CESBA criteria. The innovation in this research does not lie in the computation of the sustainability score itself, but in the way in which data both used for and obtained from calculation are organized, stored and shared among the stakeholders. The COBie spreadsheets, as well as the mapping of the sustainability data contained in them, allows for the creation of an Asset Information Model (AIM), even if not geometrical, well integrated in a BIM process. This methodology for sustainability assessment is well fitted in the BIM Bronze approach by UK Ministry of Justice (MoJ) to create and manage existing assets data in a BIM environment. Moreover, thanks to its simple but robust data structure, COBie data can be easily imported in current ComputerAided Facility Management software.
\end{abstract}

Keywords: green BIM, lean process, sustainability rating. 


\section{INTRODUCTION}

Rating systems are getting more and more complex, mainly due to the demand by clients and users to develop different versions, depending on the stage of building life cycle (e.g. new construction, operation and maintenance, refurbishment and fit-out), or accordingly to the extension (e.g. LEED-ND, DGNB New Urban District) [1]. The underpinning question concerns how to develop a methodological approach to support an additional progress, by associating more directly the aforementioned tools with computational instruments adopted in lifecycle evaluation and, in perspective, in an Internet of Things (IoT) approach. Accordingly, BIM represents a privileged environment to enable the green requirements automatic evaluation and to support decisions about sustainable strategies during the building life cycle [2]. Data exchange between BIM software and rating systems must, consequently, be based on a standard exchange protocols like COBie. Using COBie leads to a more interoperable and open access to data, which could be used by professionals in several software, in different moments of the building life, to empower collaborative environment and shared decisions.

When creating a 3D model is too onerous, MoJ proposes a model which, embeds a strong semantic information content included in COBie schema; good enough to perform analysis and operations for sustainability evaluations. The implementation of this approach, called by MoJ BIM Bronze, allows the integration of semantic and geometric information, if the model is developed further [3].

In this paper, after a brief state of the art about green BIM and sustainability rating systems, the methodology developed by the authors is presented and eventually a case study shows its possible applications and potential. This research is conducted as a case study research [4], therefore a large part of this paper is devoted to the application.

\section{STATE OF THE ART}

In this paragraph main topics held in the paper are presented, aiming at contextualising the research and providing a basis for the methodology development.

Green BIM is a wide and growing topic, including themes like sustainability assessment, development of design software more integrated over the life cycle and definition of information requirements. Literature reviews on the topic [5] [6] and researches [7] showed many possible uses of tools, software, BIM models and indicators to be used over the life cycle; they highlighted that one of the recurring issues is information management, understood as information requirements definition, data sharing and access. This is the reason why in this research authors tried to address the problem of organising information about sustainability in a robust format, with defined procedures to gather, update and share them.

A review of relevant sustainability rating protocols is important to analyse contents and relevant areas to be addressed by the methodology under development [8]. Table 1 shows that great attention is paid to energy, materials and health of the occupants; moreover it shows that each protocol has its own peculiarities, being more focused on specific aspects, like economy, process or transport. 
Table 1 Sustainability protocols comparison

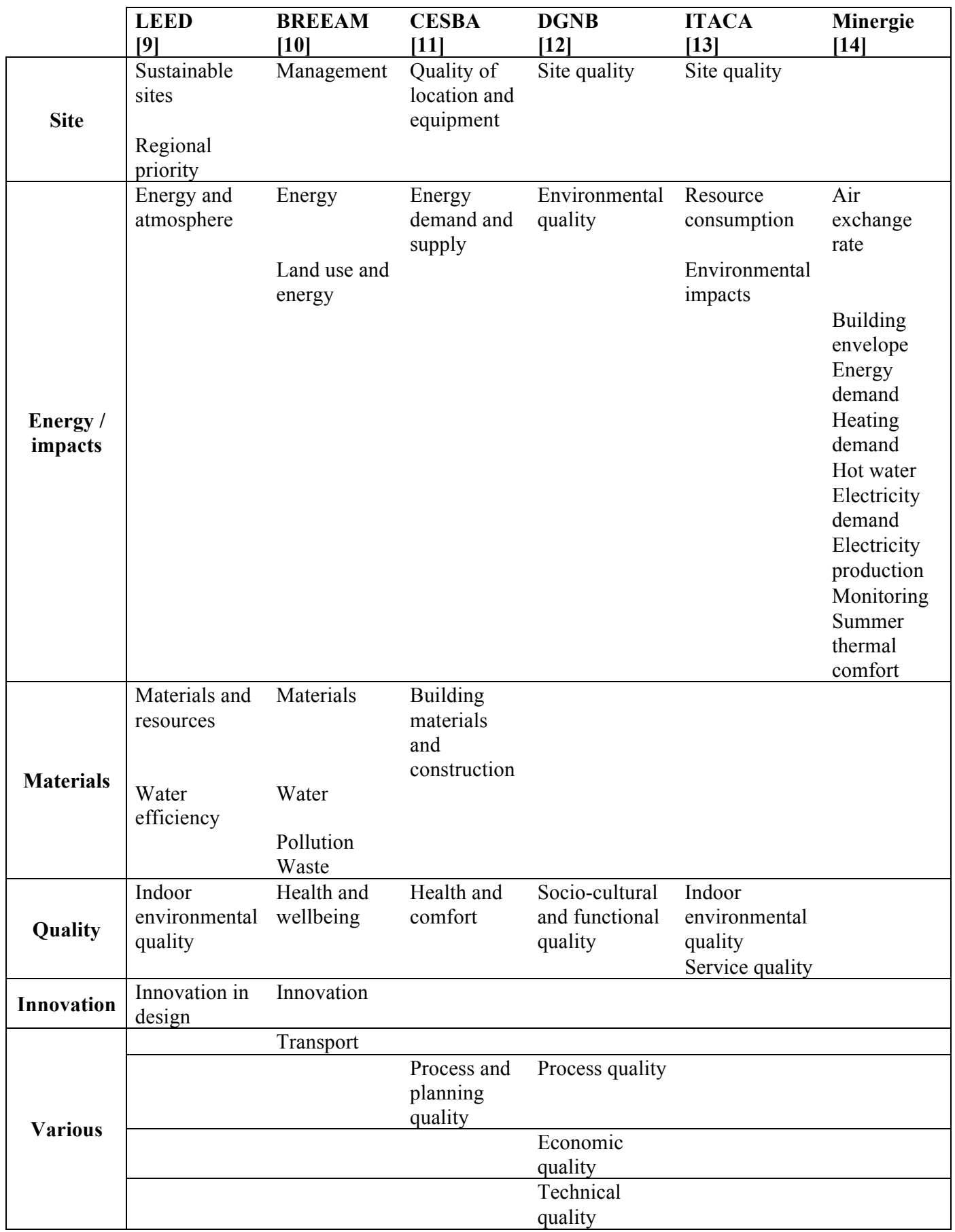

\section{GREEN BIM LEAN METHODOLOGY}

In this paragraph the methodology developed is shortly presented, aiming at outlining the main steps to be carried out to achieve: (1) a robust organisation of the information, stored in the Asset Information Model (AIM), based on COBie protocol; (2) a rating according to a sustainability assessment protocol. Figure 1 summarises the process leading from the joint analysis of rating criteria and COBie standard, to the definition of a semantic model and then to a rating. 


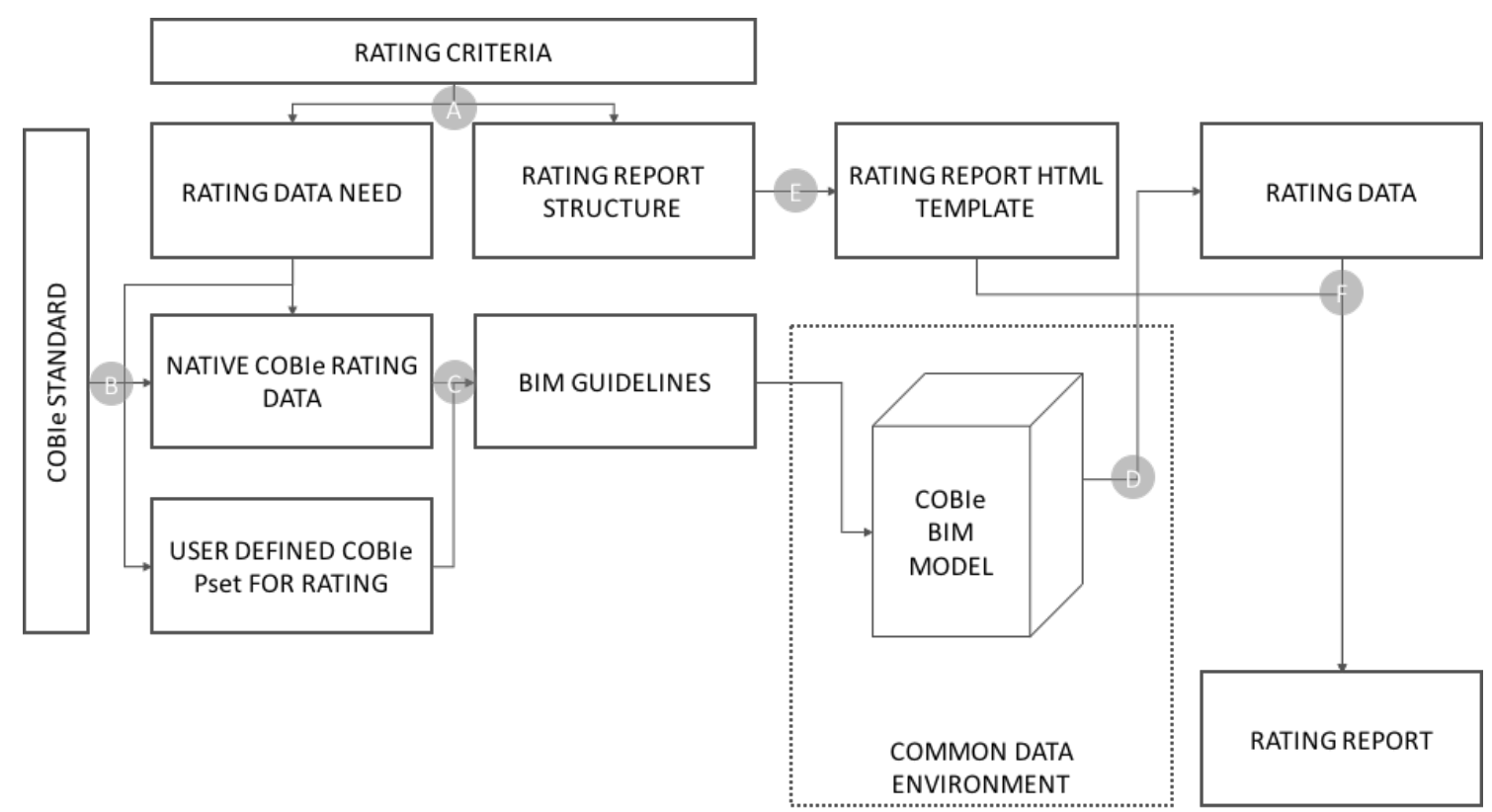

Figure 1 Scheme of the main steps of the methodology under development

Main steps to be performed are: (A) definition of rating system data needs and rating system report structure analysis; (B) COBie standard analysis and definition of data directly stored in a COBie project and creation of custom property sets; (C) creation of BIM guidelines for sustainability analysis; (D) creation of a web service to automatically extract data from IFC files stored in a BIM Server; (E) creation of an html report template according to rating report structure; (F) creation of a web app that fills the report template with data extracted from the COBie BIM model and computes the sustainability rating of the project. These steps must not be conceived as the as the only feasible procedure, but as the best to achieve the aim of the research. In this paper, only COBie has been used, not storing the data into IFC attributes, because the focus was mainly to analyse points (A) and (B), as described in the following paragraphs.

\section{CASE STUDY}

In this paragraph the methodology previously explained is applied to an existing building, to show its potential and applicability.

The building selected as a case study is a sporting club owned by a private society. The building is located in the north of Italy, in Gallarate (province of Varese). The gym, built in the $80 \mathrm{~s}$, provided limited performances in terms of spaces, functions and energy, so it has been recently refurbished, increasing also the floor area, to better satisfy users' needs (Figure 2). All the documents (drawings, reports, design documents, systems layouts, etc.) have been provided by the engineering society involved in the refurbishment.

The starting point of the application of the methodology developed to the building has been the analysis of the documentation provided. 215 documents have been checked and a hierarchical system has been adopted, so to better handle them and, more important, the data included. Three main categories (design documents, compliance with laws, building operation) have been created and then divided into sub-categories according to specific needs. Presence or absence of documents has been checked using the UNI 10998:2002 as guideline. Main goal of the due diligence has not been to check the fulfilment of Italian 
laws requirements (although they were respected), but to organise documents, so to better extract data useful for the CESBA protocol calculation.

a)

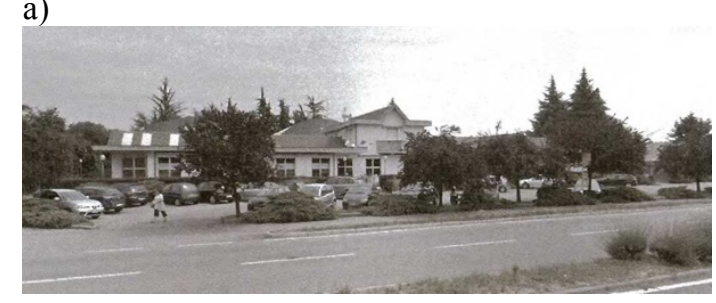

b)

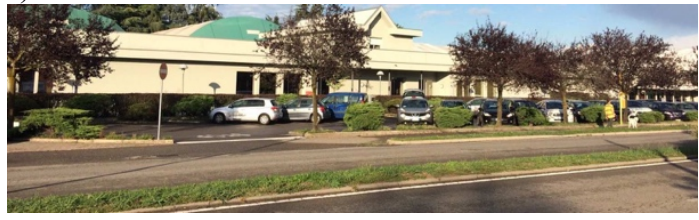

c)

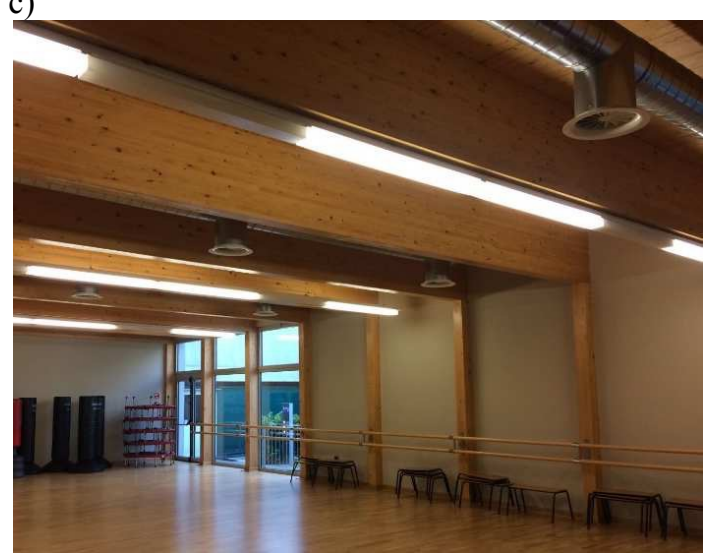

Figure 2 a) original building, b) refurbishment, external view, c) refurbishment, internal view

Data extraction from the previously organised documents has been the most effort and time consuming activity, nevertheless it cannot be compared with a complete modelling of a BIM model (intended as a 3D model with attributes and documents associated to each object). This activity allowed to perform important activities: 1) to map the data required for the CESBA protocol calculation ("CESBA - Indicator Catalogue for Public Buildings Refurbishment" has been chosen); 2) to transpose previous mentioned data into a more organised, robust and computer/human-readable format (COBie); and 3) to obtain the CESBA rating (for the criteria which have been possible to calculate).

The first step has been carried out by analysing each document according to the guidance provided by CESBA, so to match documents with the relevant criteria. As instance, for the criteria B3 (simplified calculation of efficiency) some documents about systems (schemes, descriptions, costs, etc.) have been selected (Figure 3) and associated to specific requirements of the criteria. As can be seen, not all the documents needed are present: some of them are missing, but many can be either retrieved from analysis (e.g. the correct inflation rate to be used) or with interviews to the tenant/owner (e.g. annual costs and fees).

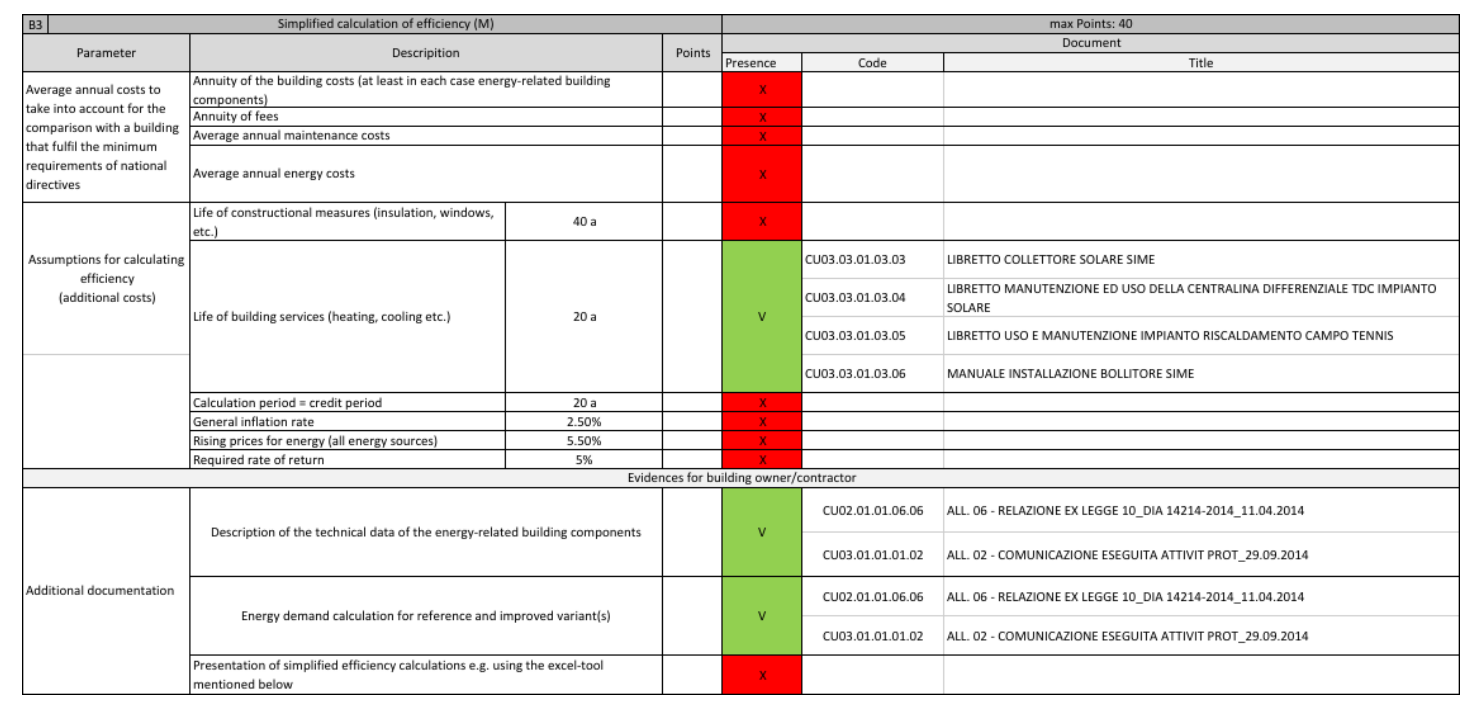

Figure 3 Mapping between documents and CESBA requirements 
The second step, more effort consuming but extremely useful especially on the long period, has been the transposition of the data from documents to the COBie spreadsheet created for the purpose. Main sheets used in this phase are: document, facility, floor, space, component and attribute. Only the information relevant for CESBA calculation have been inserted in COBie: as instance only 70 components, mainly related to systems, have been added to the "component" sheet. The "attribute" sheet has been filled with the data coming from the documents, divided by criteria, with the only purpose of retrieving them in a faster way. As instance the attributes related to the criteria D6 (hygiene and soundproofing) have been listed in the "attribute" sheet, in association with the objects (components and spaces), according to what has been found in the documents (Figure 4).

\begin{tabular}{|c|c|c|c|c|c|c|c|c|c|}
\hline $\begin{array}{l}\text { Еँ } \\
\text { Еू }\end{array}$ & 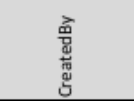 & 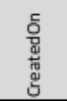 & 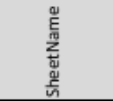 & 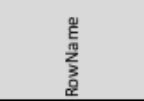 & $\frac{\stackrel{g}{3}}{\frac{\mathrm{m}}{\mathrm{m}}}$ & 蒙 & 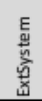 & 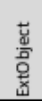 & 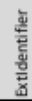 \\
\hline \multicolumn{10}{|c|}{ D2_Comfort ventilation - hygiene and soundproofing } \\
\hline \begin{tabular}{|l|} 
InternalSoundEmission \\
\end{tabular} & Eleonora_Idra & 30-Iug & Component & UTARistorante & 45 & $d B$ & & & \\
\hline \begin{tabular}{|l|} 
InternalSoundEmission \\
\end{tabular} & Eleonora_Idra & 30-Iug & Component & UTASpogliatoi_1 & 45 & $d B$ & & & \\
\hline \begin{tabular}{|l|} 
InternalSoundEmission \\
\end{tabular} & Eleonora_Idra & 30-Iug & Component & UTASpogliatoi_2 & 45 & $d B$ & & & \\
\hline \begin{tabular}{|l|} 
InternalSoundEmission \\
\end{tabular} & Eleonora_Idra & 30-lug & Component & UTAFitness & 45 & $d B$ & & & \\
\hline \begin{tabular}{|l|} 
InternalSoundEmission \\
\end{tabular} & Eleonora_Idra & 30-lug & Component & UTASaleCorsi__1 & 45 & dB & & & \\
\hline \begin{tabular}{|l|} 
InternalSoundEmission \\
\end{tabular} & Eleonora_Idra & 30-Iug & Component & UTASaleCorsi_2 & 45 & $d B$ & & & \\
\hline \begin{tabular}{|l|} 
InternalSoundEmission \\
\end{tabular} & Eleonora_Idra & 30-lug & Component & HeatingPump & 80 & $d B$ & & & \\
\hline \begin{tabular}{|l|} 
InternalSoundEmission \\
\end{tabular} & Eleonora_Idra & 30-lug & Space & BasementFloor & 30 & $d B$ & & & \\
\hline InternalSoundEmission & Eleonora_Idra & 30-lug & Space & GroundFloor & 30 & $d B$ & & & \\
\hline \begin{tabular}{|l|} 
InternalSoundEmission \\
\end{tabular} & Eleonora_Idra & 30-lug & Space & FirstFloor & 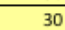 & $\mathrm{dB}$ & & & \\
\hline
\end{tabular}

Figure 4 Extract of the "attribute" sheet

More than 450 attributes have been extracted from documents and inserted in the "attribute" sheet, always in association to physical objects (facility, components), spatial objects (floors, spaces) and even to documents.

Third and last step of this case study has been the calculation of the CESBA rating of the building: this has been done manually, not only to obtain the rating, but to understand how many criteria could be fulfilled with the data currently available.

\section{RESULTS}

The result is that this process allowed to extract from the documents around the $85 \%$ of the data necessary for the calculation of the CESBA rating. The $15 \%$ missing is mainly related to information that cannot be directly retrieved from documents (either about design or operation) but calculated using other software (i.e. Passive House Planning Package and Ecosoft). The result of this assessment, although partial, is equal to 424 points. This final result, as well as the partial ones associated to single criteria, have been inserted in the "attribute" sheet, associated to the entire facility; the column "CreatedOn" has an important role, as it allows to update the attribute over the building life, updating it according to the modifications occurred, but without losing important data (otherwise contained in scattered documents).

\section{DISCUSSION}

This case study cannot be considered a full application of the methodology developed, although it shows benefits and potential of creating an Asset Information Model, without modelling the geometrical part (at least in the first steps). The analysis of this building allowed also to achieve an important result: the mapping between documents and CESBA criteria, as well as the mapping between data (organised in COBie) and the CESBA criteria. These connections can be used and further improved with other case studies, easing future assessments. 
The analysis has been affected also by the lack of some documents and data, not required by Italian laws but needed to very CESBA requirements. Nevertheless, most of the criteria have been assessed, except for the two requiring third-party software (criteria $\mathrm{C} 1$ to $\mathrm{C} 4$ and E1). The calculation has been carried out manually by the authors, as the main goal is to test the methodology; an automated algorithm would be required to speed up the calculation process.

For now, authors decided to apply the methodology only to CESBA, but the same steps can be carried out for other rating systems, facing issues related to specific criteria/protocols. The application to the building demonstrated the possibility of organising the data in a robust structure, being able to fulfil the stakeholders' needs, which in this case are represented by the client's need of organising asset information and obtaining a sustainability certification.

A possible improvement could be represented by the use of IFC (Industry Foundation Classes) for storing sustainability data: some property sets can be created and associated to specific IFC entities, so to allow protocols calculations directly from IFC models, like some researchers did form BREEAM [15]. This of course includes the modelling of the asset, but it opens for the development of automated code checking applications.

\section{CONCLUSION}

The proposed methodology can be considered an important step toward the standardisation of the information about sustainability over the life cycle, with a BIMcompliant structure and process. Having the data structured in an internationally recognised and robust format, computer and human readable like COBie, can be considered the first step to be done to enter the BIM process: indeed one of the most important tasks for an organisation willing to adopt BIM, is the definition of the strategy and of the information requirements. Moreover, the use of COBie allows to adopt the BIM approach without beginning with a geometrical model, usually very effort and time consuming; the model can be created later, when the organisation has more robust foundations about BIM processes, whilst in the meanwhile the spreadsheet can be used to structure data, to calculate ratings and eventually to connect the data to the model or to other CAFM (Computer-Aided Facility Management) software.

Some additional steps need to be performed to create a more efficient process: an important improvement would be the creation of an automatic algorithm to analyse data contained in the COBie spreadsheet and to show the results in a clear and detailed way. Nevertheless the case study really helped in the definition of the information requirements for the calculation of the CESBA rating; these can be used also in the modelling of BIM objects, with attributes embedded, so to model buildings (both existing and new construction) with the attributes ready to be filled.

Eventually, CESBA has been selected, being one of the most comprehensive protocols, but the same process can be applied to other important protocols, as well as to other relevant topics, like maintenance, energy and space management. Moreover, COBie format is compliant with the BIM Bronze approach by UK MoJ, allowing to create and manage data about existing assets in a BIM environment. 


\section{ACKNOWLEDGMENTS}

Authors greatly thank the company RIGAMONTI FRANCESCO S.p.A., for providing documents and data about the case study and Dr. Eleonora Idra for her contribute to the research.

\section{REFERENCES}

[1] Komeily A., Srinivasan R.S., (2015) A need for balanced approach to neighbourhood sustainability assessments: A critical review and analysis, Sustainable Cities and Society vol. 18, pp 32-43, 2015.

[2] Wong J.K.W., Zhou J., Enhancing environmental sustainability over building life cycles through green BIM: A review, Automation in Construction, vol. 57, pp 156-165, 2015.

[3] Ministry of Justice - MoJ, Home Office, Crown Prosecution Service - CPS, BIM2AIM quick start guide, available from: https://goo.gl/2XPBbo, [accessed: October, 2016].

[4] Yin R.K., Case study research: Design and methods. Newbury Park, CA: Sage, 1984.

[5] Wong J. K. W., Zhou J., Enhancing environmental sustainability over building life cycles through green BIM: A review, Automation in Construction, vol. 57, pp. 156-165, 2015.

[6] Lu Y., Wu Z., Chang R., Li Y., Building Information Modeling (BIM) for green buildings: A critical review and future directions, Automation in Construction, vol. 83, pp. 134-148, 2017.

[7] El-Diraby T., Krijnen T., Papagelis M., BIM-based collaborative design and sociotechnical analytics of green buildings, vol. Automation in Construction, vol. 82, pp. 5974, 2017.

[8] Tagliabue L.C., Manfren M., Sustainability indicators for buildings: network analysis and visualization, Sustainable Built Environment (SBE) Regional Conference, Zurich, June 15-17, 2016.

[9] U.S. Green Building Coucil, LEED 2009 for New Construction and Major Renovations Rating System, 2009.

[10]Building Research Establishment, BREEAM - International Non-Domestic Refurbishment, 2015.

[11]CESBA, Indicator Catalogue for Public Buildings Refurbishment 1.1, 2013.

[12] German Sustainable Building Coucil, DGNB certification system, 2017.

[13] iiSBE Italia, Protocollo ITACA Residenziale, 2011.

[14] Minergie, Guida all'uso degli standard Minergie, 2017.

[15]Ilhan B., Yaman H., Green building assessment tool (GBAT) for integrated BIMbased design decisions, Automation in Construction, vol. 70, pp. 26-37, 2016. 